\title{
Costs of health care: experience of one department of rheumatology
}

\author{
A K THOULD
}

\begin{abstract}
Little or no information exists about the costs of providing services in the National Health Service. A study was commissioned to measure the costs of running the department of rheumatology in Cornwall. The results emphasised the relative cheapness of outpatient care compared with inpatient care.
\end{abstract}

\section{Introduction}

Governments throughout the developed world have shown increasing concern in recent years about the cost of health care ${ }^{1}$ and the implications of the ever increasing spiral. Britain has addressed the problems of open ended expenditure for medical care more than most. ${ }^{2}$ One report from the United States stated that the National Health Service gives good value for money for the patient but does not record how much particular services cost and has no notion of how individual clinicians practise. In consequence comparisons about health costs are hard to make. ${ }^{23}$ The Griffiths report pointed out that doctors are the chief allocators of resources, particularly in hospital care, where costs tend to be high. ${ }^{4}$ The report called for doctors to become more accountable for their use of resources and also pointed out that the NHS lacked any continuous evaluation of its performance. Economic evaluation of health care is particularly rare. The NHS cost $6.3 \%$ of the gross national product in Britain in 1982 and accounted for $11 \cdot 3 \%$ of total government spending, ${ }^{2}$ so it is hardly surprising that concern is being expressed.

As the disabled form more than $10 \%$ of the world's total population ${ }^{5}$ we should be aware of the cost of looking after this part of the general public. This paper attempts to provide some information to promote this awareness.

\section{Methods}

In 1981 the Cornwall and Isles of Scilly Area Health Authority wished to set up an experiment in functional budgeting but first needed to know the costs of running a department. The department of rheumatology was chosen to take part in a preliminary study to evaluate these costs as it is a fairly self contained unit looking after the needs of an easily identifiable group of patients. The department is a modern one of 18 beds opened in 1978. It has its own physiotherapy and occupational therapy wings as well as a research department. It is situated next to the hydrotherapy pool and has an area for making splints and a small operating room for arthroscopy. Some of the outpatient clinics take place in the department.

A grant was obtained from the Department of Health and Social Security so that the costing survey could be carried out by the treasurer's department

Department of Rheumatology, Royal Cornwall Hospital, Truro, Cornwall

A K THOULD, MD, FRCP, consultant rheumatologist of the area health authority. The identifiable costs of running the inpatient service and one of the five weekly outpatient clinics were recorded from July to December 1981 inclusive. The costs of medical staffing, nursing, medical and surgical supplies, drugs, the central sterile supply department, radiography and pathology tests, physiotherapy, hydrotherapy, and chiropody were recorded as direct medical costs. Indirect costs such as secretarial and administration, cleaning, maintenance, heating, catering, and portering under the heading of additional general services, together with costs of ambulances and transport, were also recorded. Each visit by each patient to, for example, the physiotherapy, hydrotherapy, or chiropody service was noted and costed. Each dressing, swab, and syringe used was recorded under medical and surgical supplies. In the outpatient clinic, however, it proved impossible to identify the costs of the central sterile supply department and medical and surgical supplies as this clinic was attended by both medical and rheumatological patients. The other outpatient costs were, however, successfully clarified. Drugs for these outpatients were prescribed by their general practitioners, and the costs of chiropody and occupational therapy for outpatients fell on the community services and were not recorded. The department was satisfied, however, that with these exceptions all costs were identified and included.

The rheumatology department looks after the hospital rheumatological needs of a population of 380000 . It is staffed by one consultant, one general practitioner giving three sessions a week (at hospital practitioner grade), one senior house officer, twelve and a half (whole time equivalent) nurses, including one sister, one senior and one basic grade physiotherapist, one senior and one aid occupational therapist, and two secretarial staff.

\section{Results}

The distribution of diagnoses for the inpatients was: rheumatoid arthritis 86 , osteoarthritis 43 , ankylosing spondylitis 14 , juvenile chronic arthritis six, systemic lupus erythematosus four, back problems four, and other problems 19. Table I records the costs incurred in the six months of the study. The sums spent in the full year were therefore roughly $£ 290000$ for the inpatient services and $£ 26000$ for the outpatient clinic. Unfortunately, the costings for only one of the five weekly outpatient clinics could be

TABLE I-Actual costs (£) incurred by department of rheumatology from fuly to December 1981

\begin{tabular}{lcc}
\hline & $\begin{array}{c}\text { Inpatients } \\
\text { (No of inpatient } \\
\text { days }=2490)\end{array}$ & $\begin{array}{c}\text { Outpatients } \\
\text { (No of outpatient } \\
\text { attendances }=364)\end{array}$ \\
\hline Medical staffing & 9240 & 1260 \\
Nursing & 4460 & 350 \\
Medical and surgical supplies & 920 & Not identifiable \\
Pharmaceuticals & 1320 & Not prescribed \\
Central sterile supply department & 405 & Not identifiable \\
Radiography & 480 & 1620 \\
Pathology & 430 & 70 \\
Physiotherapy & 5840 & 1910 \\
Hydrotherapy & 3000 & Performed by community services \\
Occupational therapy & 6300 & 40 \\
Medical photography & 70 & Performed by community services \\
Chiropody & 520 & 1918 \\
Additional general services & 70069 & 1434 \\
Ambulance and transport & 572 & 12572 \\
\hline Total & 143326 & \\
\hline
\end{tabular}


monitored. This particular clinic was attended in the main by rheumatological patients but also by a few general medical patients. It subsequently became a wholly rheumatological clinic. The policy of the department is to treat most patients on an outpatient basis only. They are admitted to the ward only if their independence breaks down-for example, after a worsening of their disease. When orthopaedic procedures such as major surgery to the hip, feet, and knees are performed, however, attempts are made to carry out postoperative care in the rheumatology unit so as not to take up orthopaedic beds. Inpatient care is therefore an interlude in the overall general management of patients. The costs of the other outpatient clinics are probably higher than those of the one studied as they tend to be much busier. They are strategically spread round the county to minimise patients' travelling. This inevitably increases the travelling time and costs of the doctors who service them, who have to cover long distances to and from the central department. The outpatient costs for 1981, therefore, were probably a minimum of $£ 25000$ for each of the five clinics-that is, $£ 125000$ in total. Table II shows the unit cost for each inpatient day and each outpatient attendance. As the mean duration of stay for a rheumatological patient was 14 days and the daily cost $£ 57.56$ the average mean cost for each patient on each admission was $£ 805 \cdot 84(£ 57 \cdot 56 \times 14)$. Table III sets out the distribution of the population of Cornwall at risk by age.

TABLE II-Unit costs (£) for each inpatient day and outpatient attendance at department of rheumatology

\begin{tabular}{lcc}
\hline & $\begin{array}{c}\text { Each } \\
\text { inpatient day }\end{array}$ & $\begin{array}{c}\text { Each } \\
\text { outpatient attendance }\end{array}$ \\
\hline Direct medical costs & $29 \cdot 9$ & $25 \cdot 33$ \\
Additional general services & $28 \cdot 14$ & $5 \cdot 27$ \\
Ambulance and transport & $00 \cdot 23$ & 3.94 \\
\hline Total & $57 \cdot 56$ & 34.54 \\
\hline
\end{tabular}

TABLE III-Distribution of population of Cornwall by age ${ }^{6}$

\begin{tabular}{lrrrrrr}
\hline Age (years): & $0-16$ & $17-34$ & $35-44$ & $45-64$ & $65-74$ & $\geqslant 75$ \\
Proportion (\%): & $21 \cdot 2$ & $25 \cdot 1$ & $12 \cdot 2$ & $20 \cdot 0$ & $14 \cdot 5$ & $7 \cdot 1$ \\
\hline
\end{tabular}

Because the department deals with chronic disease a large proportion of the patients are seen regularly, and they are admitted for inpatient care only when a medical, surgical, or rehabilitation problem arises that cannot be dealt with on an outpatient basis. The patients therefore tend to be both inpatients and outpatients. Patients being treated with gold or penicillamine require long term outpatient care for many years.

Although the mean stay for inpatients was 14 days, this conceals the fact that those with ankylosing spondylitis were admitted in groups of four for 21 days for intensive hydrotherapy. Several of the patients with rheumatoid arthritis had dermal infarction with vasculitis of the legs, and their mean stay was 84 days. Most patients with rheumatoid arthritis or osteoarthritis stayed for about the mean of 14 days unless they were having postoperative care for elective orthopaedic surgery, when their mean stay was 10 days. The mean number of patients seen in the clinic each time was 18 , of whom four were new patients and 14 patients being followed up. Unfortunately, the costings were performed on the smallest clinic while the consultant was sometimes away on sick leave, which meant that the number of patients seen was much smaller than usual.

\section{Discussion}

I have not found other published costings for a rheumatology department so cannot make comparisons, but several points are evident. A study of the composition of the disabled population derived from statistics on attendance allowances shows, not surprisingly, that the prevalence of disability rises sharply with age. The proportion of the disabled who have musculoskeletal disorders rises from $10.3 \%$ in those aged under 60 years to $19 \cdot 7 \%$ in those over $60 .^{7}$ Rheumatology perhaps more than any other specialty practises the concept of total care in looking after patients in partnership with the remedial and nursing professions. ${ }^{8}$ In view of the huge numbers of patients and the long time span required to look after people with chronic arthritis the costs need to be known. Health care is much cheaper in Britain than in the United States. ${ }^{2}$ In 1982 health expenditure in the United States was $\$ 1265.00$ per person while in Britain it was $\$ 386 \cdot 16$. The NHS has over one million employees and in 1983 cost over $£ 1500 \mathrm{~m}$. The NHS has been lucky that at a time when the economy has been stagnant there has been a real shift of resources into the service of about $2 \%$ in $1983 .{ }^{9}$ The national pocket, however, is not bottomless. About $10 \%$ of the cost of the health service is spent on drugs. ${ }^{10}$ Interestingly, in this survey the proportion of inpatient costs spent on drugs was only $1 \%$

The population in Cornwall has a fairly high proportion of people of pensionable age, particularly those aged 75 or over (table III). The population density is only 1.21 persons a hectare (the total population density for England and Wales is 3.24 a hectare).${ }^{6}$ Handicap tends to be more severe in the elderly, and the prevalence of arthritis rises substantially with age. The prevalence of all forms of arthritis rises from 5\% in those aged $16-44$ to $41 \%$ in those aged 65 or more. ${ }^{11}$ The elderly make proportionately much greater demands on the health service than other age groups. ${ }^{12}$ Arthritis and rheumatism cause the loss of 37.5 million working days each year by men alone with a consequent huge economic loss to the country. About $1 \cdot 1$ million people in the United Kingdom are impaired by rheumatic disorders and, of these, $3 \%$ are confined to bed, $1 \%$ to a wheelchair, and $12 \%$ to their homes. ${ }^{13}$ The cost of providing health care for this large group is bound to be high.

As the population in Cornwall rises so does the demand made on the rheumatology services. From 1971 to 1981 the population of the county rose by $13.3 \%$, but the proportion of people of pensionable age rose by $16.2 \%$. The number of people in the county aged 60 or over in 1981 was 101860 , and 23349 pensioners lived alone. ${ }^{6}$ The implications for the department of rheumatology and its ability to provide adequately for these people's need give cause for considerable concern, particularly as the population in the county is still rising rapidly. In 1981 some 416 new patients and 3661 follow up outpatients were seen in total. This had risen by the next year to 560 new patients and 4408 follow up outpatients-rises of $35 \%$ and $20 \%$, respectively, in one year. ${ }^{14}$ The rise has continued since to about 1000 new patients and 6000 follow up attendances, but the resources to deal with the problem have not risen at all. Increasingly, therefore, we are faced with a population in the county that is widely scattered and steadily aging and that will probably produce steeply increasing numbers of people disabled with arthritis. Dealing with their problems will probably be costly. If there is no increase in resources it is highly unlikely that any more people can be seen by a service staffed by only one consultant with only 18 available beds without a sharp reduction in the quality of the service given to each patient. Fundamental choices about priorities will have to be made. If more patients are seen then less time can be given to each, probably leading to either a drop in standards or certain categories of patients forgoing advice and treatment altogether. In 1981, 354 inpatients were admitted to the rheumatology ward, and in 1982 this had increased by $9 \%$ to $387 .{ }^{14}$ Clearly, the number of days spent as an inpatient by each person on each admission had decreased, bearing in mind that the ward is always full. Attempts to see more people in each clinic and admit more patients to each bed each year, however, have now reached their limit unless there is to be a drastic deterioration in the quality of care given to each patient. This dilemma must be increasingly common in rheumatology departments up and down the country.

Table II shows the distribution of costs. For inpatient care the medical, supplies, pharmaceutical, and investigative costs form a fairly small proportion of the total. The major costs are hotel costs (listed as additional general services) and the cost of providing nursing care. Physiotherapy, hydrotherapy, and occupational therapy together cost half as much again as the medical costs. Transport and chiropody costs are small. If the money spent on inpatient care is to be spent more cost effectively then the greatest savings may be obtained in the hotel costs. By contrast, in outpatient care the most money is spent on hydrotherapy, physiotherapy, and medical staffing and nursing costs are small. Transport costs form a much higher proportion, as might be expected. The low 
radiology, pathology, and pharmaceutical costs reflect the policy of the unit to avoid unnecessary investigations and drug usage.

True cost containment has been defined as reducing the inflow of health resources without reducing effective health care. ${ }^{15}$ This, however, is difficult to achieve with the open ended commitment undertaken by the health service. One way to contain health costs is to make the patient pay part of the cost ${ }^{16}$ but this is done in only a limited way in this country and is contrary to the fundamental aim of a service designed to be free at the time of need. One way of improving resources for underprivileged areas is to iron out the inequalities in health provision between regions, ${ }^{17}$ but this has been only partially successful and fails to contain unit costs for each patient, though it perhaps is a more efficient way of spending the available money. The doctor is left to act as society's agent in the rationing process ${ }^{18}$ whether we like it or not, but this is not an ideal solution. In the face of inflation, however, the ever increasing needs of an aging population, the costs of new technology, and the public wish for ready and rapid access to effective health services may well prove irreconcilable. Prevention of illness has been largely neglected by the NHS, 5 and perhaps combining this with intensive health education might ease some of the pressures.

I am grateful to Mr G G Roberts, treasurer of the Cornwall and Isles of Scilly Area Health Authority, for permission to publish the data in this paper.

\section{References}

1 Organisation for Economic Cooperation and Development. Paris: OECD, 1977. (OECD studies in resource allocation No 4 .

2 Ingleheart JK. Health policy report: the British National Health Service under the conservatives. Part I. N Engl F Med 1983;309:1264-8.

3 Ingleheart JK. Health policy report: the British National Health Service under the conservatives. Part II. N Engl f Med 1983;310:63-7.

4 National Health Service Management Inquiry. Report. London: DHSS, 1983. (Griffiths report.) 5 National Health Service Management Inquiry. Report. Lo

6 O'Neill P. Health crists 2000 . London: Heinemann, 1983. in Great Britain 1973-74. Health Trends 1974;6:66-9.

Dixon AStJ. Clinical rheumatology has advanced. Br Med f 1977;i: 1015-6.

8 Klein R. The NHS and the theatre of inadequacy. Universities Quarterly: Culture, Education and Society 1983;37:210-5.

9 Anonymous. Doctors and the drug industry [Editorial]. Br Med f 1983;286:579-80.

10 Arthritis and Rheumatism Council. Arthritis and disability. Report. London: Arthritis and Rheumatism Council, 1981

11 Department of Health and Social Security. A happier old age. A discussion document on elderly people in our society. London: HMSO, 1978.

12 Arthritis and Rheumatism Council. Arthritis and rheumatism. Everybody's problem. A report on the occurrence of rheumatic disorders in different parts of the country. London: Arthritis and Rheumatism Council, 1978.

13 Cornwall and Isles of Scilly Health Authority. General information handbook. Truro: Cornwall and Isles of Scilly Health Authority, 1983.

14 Ginsberg E. Cost containment-imaginary and real. N Engl f Med 1983;308:1220-4.

14 Ginsberg E. Cost containment-imaginary and real. N Engl f Med 1983;308:1220-4.

15 Welch H. Cost containmentimaginary an 1983;287:1115-8.
1980

17 Schwartz WB, Aaron HJ. Rationing hospital care: lessons from Britain. $N$ Engl $\mathrm{J} \mathrm{Med}$ 1984;310:52-6.

18 Office of Population Censuses and Surveys. Census 1981. County report. London: HMSO, 1982.

(Accepted 9 fuly 1985)

\section{Medicolegal}

\section{Doctors and blood tests}

\section{BY OUR LEGAL CORRESPONDENT}

If a driver suspected of excessive drinking asks to give a sample of urine rather than blood on the grounds of his repugnance to giving blood a medical opinion is required as to the validity of the request and that opinion must be given by a doctor not a police constable.

After arrest by the West Yorkshire police a driver provided two specimens of his breath on a Lion Intoximeter at a police station. The first and second specimens registered respectively 41 and 40 $\mu \mathrm{g} / 100 \mathrm{ml}$ of breath. In those circumstances section $8(6)$ of the Road Traffic Act 1972 gives the driver the right to require that the specimens of breath be replaced by a specimen of blood or urine. The Act provides: "The question whether it is to be a specimen of blood or urine shall be decided by the constable making the requirement, except that if a medical practitioner is of the opinion that for medical reasons a specimen of blood cannot or should not be taken the specimen shall be a specimen of urine."

Because West Yorkshire Police have a standing order (on hygienic grounds) that specimens should normally be of blood rather than urine the police officer offered the driver the opportunity of giving a blood sample without the alternative of a sample of urine. The driver declined to give a blood sample, because he did not like needles and some years previously had fainted when blood was taken for a test. The constable decided that that was not a valid excuse, and the driver was charged and convicted of driving a motor car having consumed excess alcohol on the basis of the evidence of his breath analysis.

The driver's conviction was set aside on appeal to Leeds Crown Court. The Divisional Court of the Queen's Bench Division dismissed the appeal of the police against the decision of Leeds Crown Court.' The divisional court held that the police officer was wrong to deprive the driver of the opportunity to obtain a medical opinion which might have supported his wish not to have a blood test. In previous cases the court decided that repugnance to giving a blood sample was capable of being a reasonable excuse for failure to provide such a sample but only when repugnance amounted to a phobia recognised by medical science. The Act designated the medical practitioner as the sole person entitled to deprive the subject of the opportunity to provide a specimen of urine when medical reasons are said to be relevant. The court indicated its view that the chances of the driver obtaining a favourable medical opinion were poor.

The practical result of this decision is that doctors may be requested to attend the police station more frequently.

\section{Reference}

1 Anonymous. Medical reason for blood sample refusal. The Times 1985 Aug 27:12(cols 1-4). 